\title{
Computational Study of Some Double Headed Acyclo-C-Nucleosides
}

\section{Sarah Amara ${ }^{1 *}$, Noureddine Tchouar $^{1}$ and Salah Belaidi ${ }^{2}$}

\author{
${ }^{1}$ Laboratory of Modeling and Optimization of Industrials Systems, Faculty of Chemistry, University \\ of Sciences and Technology of Oran Mohamed Boudiaf USTO MB, P. O. Box 1505 El-M'naouer, \\ Oran 31000, Algeria.
}

${ }^{2}$ Group of Computational and pharmaceutical chemistry, Laboratory of Molecular Chemistry and Environment, University of Biskra, 07000, Algeria.

${ }^{*}$ E-mail : amara2010sarah@yahoo.fr

Keywords: acyclo-C-nucleoside, molecular structure, AM1, HF, DFT.

ABSTRACT. In the present paper we have a focus in a study of theoretical characterization of three double headed acyclo-C-nucleosides, which are a recent target of experimental studies. The structural and electronic properties of double headed acyclo-C-nucleosides, 1,4-bis(3-mercapto- $1 \mathrm{H}$ 1,2,4-triazol-5-yl)butane-1,2,3,4-tetrol, 1,4-bis(4-amino-5-mercapto-4H-1,2,4-triazol-3-yl)butane1,2,3,4-tetrol and 5,5'-(1,2,3,4-tetrahydroxybutane-1,4-diyl)bis(1,3,4-oxadiazole-2(3H)-thione), have been investigated theoretically by performing semi-empirical molecular orbital, ab initio Hartree-Fock (HF) and Density Functional Theory (DFT) calculations. Geometries of the three molecules are optimized at the level of Austin Model 1 (AM1). The electronic properties and relative energies of the molecules have been calculated by HF and DFT in the ground state.

\section{INTRODUCTION}

Many important advances have occurred in the field of acyclo-nucleosides [1,2] and Cnucleosides.[3-10] Indeed, the modern structural features of nucleosides are somewhat different from those present in poly-ribonucleotides RNA and DNA,[11] by means of variations in sugar, heterocyclic moieties and the various modes of attachments between the two major components (sugar and heterocycle).

The literature of the new kinds of nucleosides is increasing and a lot of variations and kinds of nucleosides with dinuclear nucleosides [12,13] and others were also reported.[14,15]

The wide occurrences of heterocyclic compounds in bioactive natural products and pharmaceuticals have made them as important synthetic targets. The 1,2,4-triazoles and 1,3,4oxadiazoles represent classes of heterocyclic compounds of great importance in biological chemistry.[16-19] The therapeutic effects of compounds containing 1,2,4-triazole and 1,3,4oxadiazole rings have been well studied for a number of pathological conditions.

1,2,4-triazoles and their derivatives are found to be associated with various biological activities such as anticonvulsant,[20,21] antifungal,[22-24] anticancer,[25-28] anti-inflammatory [29-31] and antibacterial properties.[32-34] Also, a series of 1,2,4-triazole derivatives have been patented and extensively employed in agriculture.[35]

Derivatives of 1,3,4-oxadiazole have been found to possess a wide spectrum of pharmacological, medical, and biological activities.[36,37]

In this study, double headed acyclo-C-nucleosides bearing 1,2,4-triazole and 1,3,4-oxadiazole rings, 1,4-bis(3-mercapto-1H-1,2,4-triazol-5-yl)butane-1,2,3,4-tetrol (1), 1,4-bis(4-amino-5mercapto-4H-1,2,4-triazol-3-yl)butane-1,2,3,4-tetrol (2), and 5,5'-(1,2,3,4-tetrahydroxybutane-1,4diyl)bis(1,3,4-oxadiazole-2(3H)-thione) (3) (Figure 1.), tested in vitro against some gram positive and gram negative bacteria, [38] have been investigated theoretically by performing semi-empirical molecular orbital, ab initio Hartree-Fock (HF) and Density Functional Theory (DFT) calculations. 
Because of the antibacterial activity of these double headed acyclo-C-nucleosides, we have investigated the structural features and electronic properties theoretically in this work.

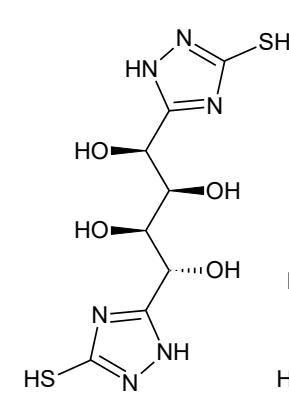

1<smiles>Nn1c(S)nnc1C(O)C(O)C(O)C(O)c1nnc(S)n1N</smiles>

2<smiles>OC(c1n[nH]c(=S)o1)C(O)C(O)[C@H](O)c1n[nH]c(=S)o1</smiles>

3

Fig. 1. Chemical structures of the studied molecules

\section{COMPUTATIONAL METHODS}

All theoretical calculations in this work were performed using the computational methods implemented in the GAUSSIAN09 package.[39] Geometry optimization of the studied compounds was done by performing the semi-empirical molecular orbital theory at the level AM1. The electronic properties have been calculated by applying ab initio Hartree-Fock (HF) calculations with $6-31+\mathrm{G}(\mathrm{d}, \mathrm{p})$ basis set and the Density Functional Theory (DFT) at the B3LYP/6-31+G(d,p) levels of theory. The hybrid Becke 3-Lee-Yang-Parr (B3LYP) exchange correlation functional was applied for DFT calculations.[40,41]

\section{RESULTS AND DISCUSSION}

Some molecular data for the studied molecules are given in Table 1.

Table 1. Some molecular data for the compounds studied

\begin{tabular}{ccccccccccc}
\hline Molecules & \multicolumn{3}{c}{$(1)$} & \multicolumn{3}{c}{$(2)$} & \multicolumn{3}{c}{$(3)$} \\
\hline Chemical formula & \multicolumn{3}{c}{$\mathrm{C}_{8} \mathrm{H}_{12} \mathrm{~N}_{6} \mathrm{O}_{4} \mathrm{~S}_{2}$} & \multicolumn{3}{c}{$\mathrm{C}_{8} \mathrm{H}_{14} \mathrm{~N}_{8} \mathrm{O}_{4} \mathrm{~S}_{2}$} & \multicolumn{3}{c}{$\mathrm{C}_{8} \mathrm{H}_{10} \mathrm{~N}_{4} \mathrm{O}_{6} \mathrm{~S}_{2}$} \\
\hline Quantity & \multicolumn{3}{c}{ Value } & \multicolumn{4}{c}{ Value } & \multicolumn{5}{c}{ Value } \\
& $\mathrm{AM} 1$ & $\mathrm{HF}$ & $\mathrm{DFT}$ & $\mathrm{AM} 1$ & $\mathrm{HF}$ & $\mathrm{DFT}$ & $\mathrm{AM} 1$ & $\mathrm{HF}$ & $\mathrm{DFT}$ \\
Electrons & 110 & 166 & 166 & 122 & 182 & 182 & 110 & 166 & 166 \\
Doubly occupied levels & 55 & 83 & 83 & 61 & 91 & 91 & 55 & 83 & 83 \\
Total orbitals & 92 & 448 & 448 & 102 & 496 & 496 & 90 & 438 & 438 \\
\hline
\end{tabular}

The optimized structures of the studied molecules are shown in Figure 2.
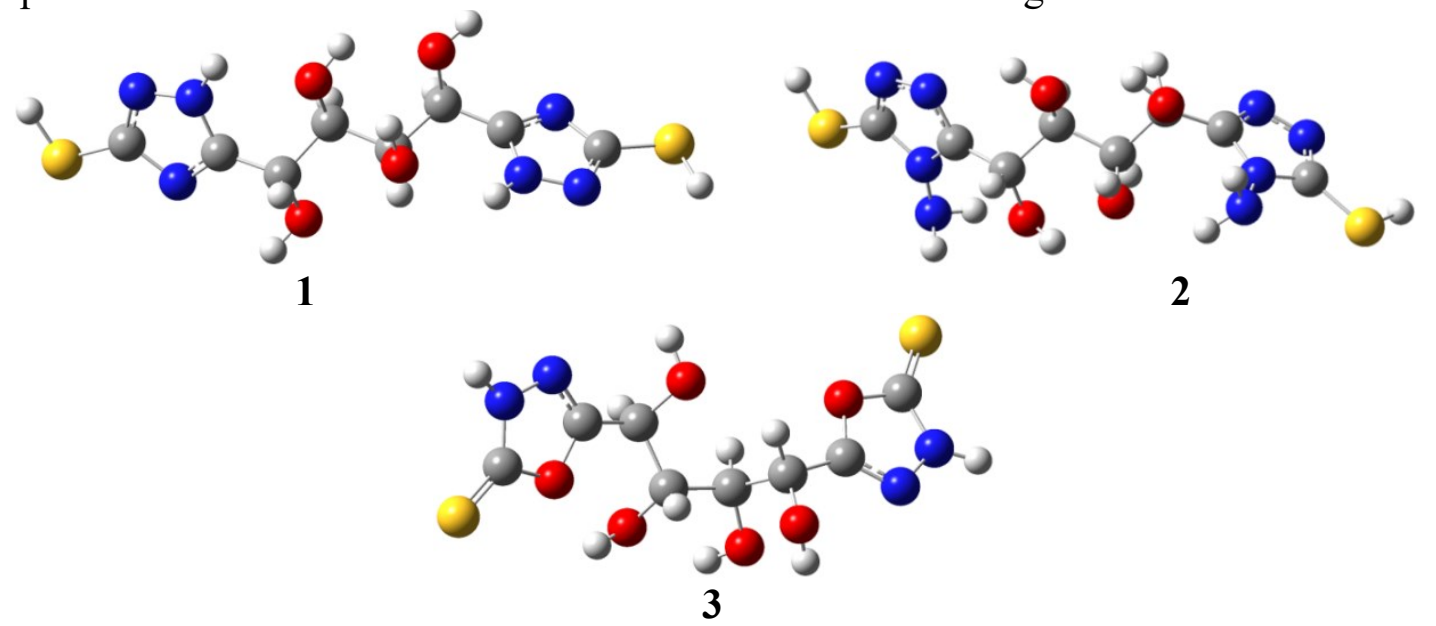

Fig. 2. Optimized structures of the studied molecules

(Optimization performed by AM1 method) 
The geometry optimizations of AM1 method yield non-planar structures for the molecules $\mathbf{1}, \mathbf{2}$ and 3.

The optimized structure parameters of each double headed acyclo-C-nucleoside by HF and DFT levels with $6-31+G(d, p)$ basis set are listed in Tables 2,3 and 4, in accordance with the atom numbering scheme given in Figures 3, 4 and 5 respectively.

From the theoretical values it is found that general geometries of carbon chain moieties of the three molecules gave almost similar bond lengths, whereas the torsion angle $\mathrm{C} 1-\mathrm{C} 2-\mathrm{C} 3-\mathrm{C} 4$, is $164.272^{\circ}$ (HF) and $164.064^{\circ}$ (DFT), for the molecule $1,-169.763^{\circ}$ (HF) and $-169.619^{\circ}$ (DFT) for the molecule 2 and $85.244^{\circ}$ (HF) and $85.003^{\circ}$ (DFT) for the molecule 3.

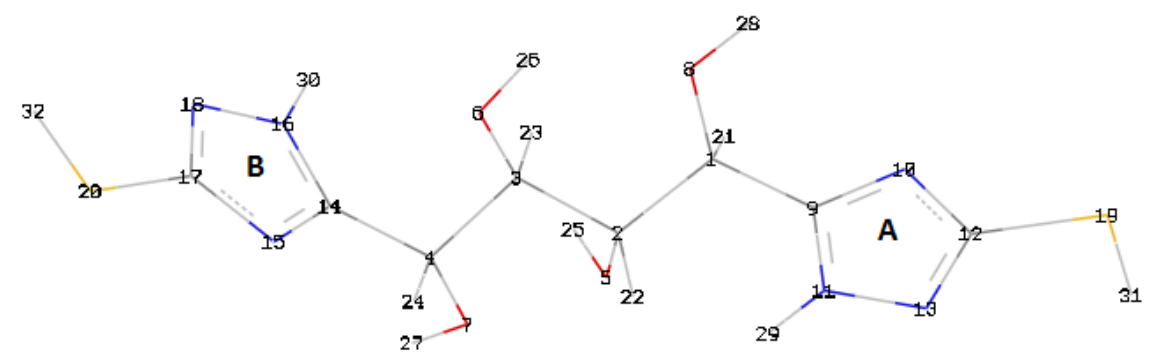

Fig. 3. Atom numbering adopted in this study for molecule 1

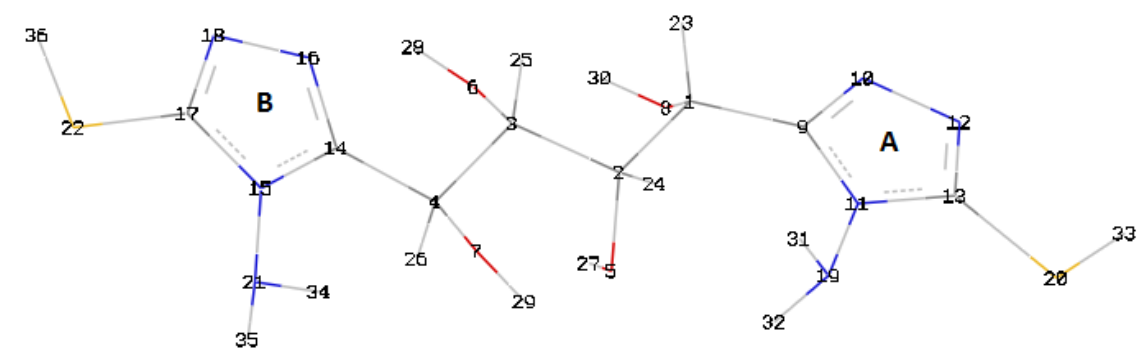

Fig. 4. Atom numbering adopted in this study for molecule 2

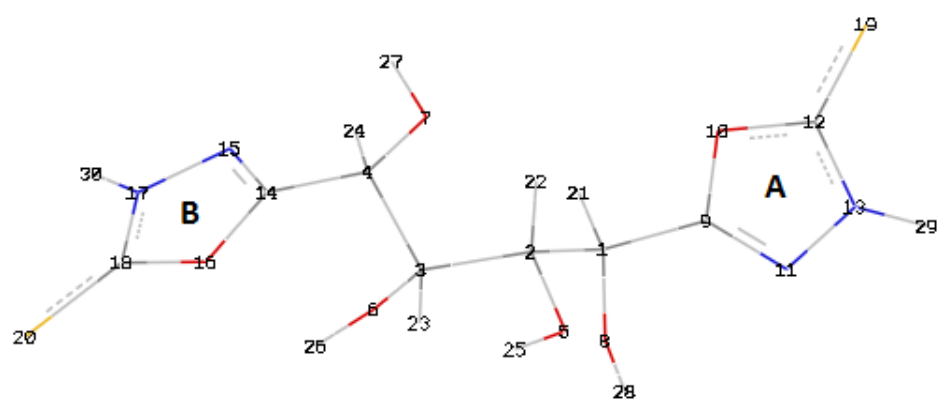

Fig. 5. Atom numbering adopted in this study for molecule 3

The total energy, highest occupied and the lowest unoccupied molecular orbital (HOMO and LUMO, respectively) energies, energetic gap (LUMO-HOMO, $\Delta \mathrm{E}$ ) and the dipole moment $\mu$ (in Debyes) for the studied molecules are given in Table 5.

The molecule 1 has a total energy value of -1731.121 a.u. by HF and -1737.159 a.u. by DFT methods. The $\triangle \mathrm{E}$ (LUMO - HOMO gap) of this molecule is 0.401 a.u. (HF) and 0.206 a.u. (DFT), the resultant dipole moment is 3.0 Debyes by HF and DFT methods.

The total energy of the molecule 2 is -1841.089 a.u. by HF and -1848.510 a.u. by DFT methods. This molecule needs energy of 0.378 a.u. according to HF calculations and 0.195 a.u. according to DFT calculations to reach the excited state. The resultant dipole moment is 6.8 and 7.0 Debyes by HF and DFT methods respectively. 
Table 2. Geometrical parameters optimized of molecule 1

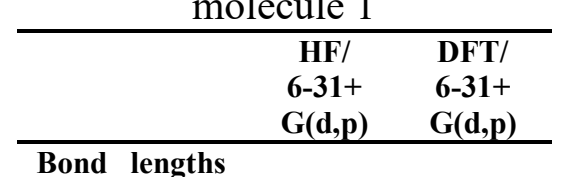

$\left(\mathrm{A}^{\circ}\right)$

Chain :

C9-C1

$\mathrm{C} 1-\mathrm{C} 2$

$\mathrm{C} 2-\mathrm{C} 3$

$\mathrm{C} 3-\mathrm{C} 4$

C4-C14

$\mathrm{C} 1-\mathrm{O} 8$

$\mathrm{C} 2-\mathrm{O} 5$

$\mathrm{C} 3-\mathrm{O} 6$

C4-O7

Ring : A

C9-N11

N11-N13

N13-C12

C12-S19

C12-N10

N10-C9

Ring : B

C14-N16

N16-N18

N18-C17

C17-S20

C17-N15

N15-C14

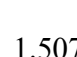

1.528

1.536

1.530

1.509

1.411

1.403

1.407

1.392

1.322

1.345

1.295

1.758

1.352

1.306

\subsection{2}

1.537

1.542

1.538

1.507

1.445

1.428

1.434

1.416

1.347

1.358

1.330

1.765

1.363

1.330

Bond angle

( $\left.{ }^{\circ}\right)$

N13-C12-S19 $124.481 \quad 123.976$

N18-C17-S20 $124.603 \quad 124.189$

$\begin{array}{lll}\mathrm{C} 1-\mathrm{C} 9-\mathrm{N} 10 & 122.754 & 123.760\end{array}$

C4-C14-N15 $\quad 122.944 \quad 123.009$

Dihedral angle

( $\left.{ }^{\circ}\right)$

C2-C1-C9-N10 $161.166 \quad 157.741$

C3-C4-C14-N15 $137.453 \quad 136.960$

C1-C2-C3-C4 $164.272 \quad 164.064$
Table 3. Geometrical parameters optimized of molecule2

\begin{tabular}{ccc}
\hline HF/ $/$ DFT/ \\
\\
6-31+ & $\mathbf{6 - 3 1 +}$ \\
G(d,p) & $\mathbf{G ( d , p )}$ \\
\hline Bond lengths & &
\end{tabular}

$\left(\mathbf{A}^{\circ}\right)$

Chain :

C9-C1

$\mathrm{C} 1-\mathrm{C} 2$

$\mathrm{C} 2-\mathrm{C} 3$

$\mathrm{C} 3-\mathrm{C} 4$

$\mathrm{C} 4-\mathrm{C} 14$

$\mathrm{C} 1-\mathrm{O} 8$

$\mathrm{C} 2-\mathrm{O} 5$

$\mathrm{C} 3-\mathrm{O} 6$

$\mathrm{C} 4-\mathrm{O} 7$

Ring : A

C9-N11

N11-N19

N11-C13

$\mathrm{C} 13-\mathrm{S} 20$

C13-N12

N12-N10

N10-C9

Ring : B

C14-N15

N15-N21

N15-C17

$\mathrm{C} 17-\mathrm{S} 22$

C17-N18

N18-N16

N16-C14

Bond angle

$\left({ }^{\circ}\right)$

N11-C13-S20 $122.291 \quad 121.879$

N15-C17-S22 $122.241 \quad 121.799$

$\begin{array}{lll}\mathrm{C} 1-\mathrm{C} 9-\mathrm{N} 11 & 126.900 & 126.587\end{array}$

C4-C14-N15 $\quad 125.675 \quad 126.199$

Dihedral

angle $\left(^{\circ}\right)$

C2-C1-C9-N10 $97.299 \quad 100.137$

C3-C4-C14-N16 $\quad-16.196 \quad-19.880$

\begin{tabular}{lll}
$\mathrm{C} 1-\mathrm{C} 2-\mathrm{C} 3-\mathrm{C} 4$ & -169.763 & -169.619 \\
\hline
\end{tabular}
Table 4. Geometrical parameters optimized of molecule3

\begin{tabular}{lcc}
\hline & HF/ & DFT/ \\
& $\mathbf{6 - 3 1 +}$ & $\mathbf{6 - 3 1 +}$ \\
$\mathbf{G ( d , p )}$ & $\mathbf{G ( d , p )}$ \\
\hline Bond lengths & & \\
(A) $^{\circ}$ Chain : & & \\
C9-C1 & 1.505 & 1.506 \\
C1-C2 & 1.537 & 1.548 \\
C2-C3 & 1.543 & 1.549 \\
C3-C4 & 1.541 & 1.550 \\
C4-C14 & 1.507 & 1.506 \\
C1-O8 & 1.384 & 1.407 \\
C2-O5 & 1.396 & 1.419 \\
C3-O6 & 1.404 & 1.429 \\
C4-O7 & 1.388 & 1.414 \\
Ring : A & & \\
C9-O10 & 1.350 & 1.369 \\
O10-C12 & 1.343 & 1.387 \\
C12-S19 & 1.649 & 1.644 \\
C12-N13 & 1.325 & 1.356 \\
N13-N11 & 1.368 & 1.378 \\
N11-C9 & 1.258 & 1.288 \\
& & \\
Ring : B & & \\
C14-O16 & 1.348 & 1.366 \\
O16-C18 & 1.350 & 1.398 \\
C18-S20 & 1.641 & 1.636 \\
C18-N17 & 1.328 & 1.358 \\
N17-N15 & 1.367 & 1.376 \\
N15-C14 & 1.258 & 1.288 \\
& & \\
Bond angle & & \\
() & & \\
O10-C12-S19 & 125.557 & 125.744 \\
O16-C18-S20 & 125.275 & 125.408 \\
C1-C9-N11 & 129.117 & 128.246 \\
C4-C14-N15 & 127.078 & 125.991 \\
Dihedral & & \\
angle ( $\left.{ }^{\circ}\right)$ & & \\
C2-C1-C9-O10 & 60.187 & 62.016 \\
C3-C4-C14-O16 & -43.302 & -43.022 \\
C1-C2-C3-C4 & 85.244 & 85.003 \\
\hline
\end{tabular}


Table 5. The Total energy, MO energy of HOMO, LUMO, $\Delta \mathrm{E}$ (in a.u.) and the dipole moment, $\mu$ (in Debye) for the studied molecules

\begin{tabular}{ccccccc}
\hline Molecule & Method & Total energy & HOMO & LUMO & $\Delta \mathbf{E}$ & $\boldsymbol{\mu}$ \\
\hline $\mathbf{1}$ & $\mathrm{HF} / 6-31+\mathrm{G}(\mathrm{d}, \mathrm{p})$ & -1731.121 & -0.346 & 0.055 & 0.401 & 3.023 \\
& $\mathrm{DFT} / 6-31+\mathrm{G}(\mathrm{d}, \mathrm{p})$ & -1737.159 & -0.244 & -0.038 & 0.206 & 2.967 \\
\hline \multirow{2}{*}{} & $\mathrm{HF} / 6-31+\mathrm{G}(\mathrm{d}, \mathrm{p})$ & -1841.089 & -0.333 & 0.045 & 0.378 & 6.812 \\
& $\mathrm{DFT} / 6-31+\mathrm{G}(\mathrm{d}, \mathrm{p})$ & -1848.510 & -0.236 & -0.041 & 0.195 & 6.972 \\
\hline \multirow{3}{*}{} & $\mathrm{HF} / 6-31+\mathrm{G}(\mathrm{d}, \mathrm{p})$ & -1770.744 & -0.327 & 0.044 & 0.371 & 3.627 \\
& $\mathrm{DFT} / 6-31+\mathrm{G}(\mathrm{d}, \mathrm{p})$ & -1777.587 & -0.233 & -0.062 & 0.171 & 4.029 \\
\hline
\end{tabular}

For the molecule 3, the total energy value is -1770.744 a.u. by HF and -1777.587 a.u. by DFT methods. The $\triangle \mathrm{E}$ (LUMO - HOMO gap) of this molecule is 0.371 a.u. (HF) and 0.171 a.u. (DFT), the resultant dipole moment is 3.6 Debyes according to HF calculations, while the calculated value according to DFT calculations is 4.0 Debyes.

The calculated dipole moments by the two methods indicate that each studied molecule is polar (hydrophilic) and active, and may interact with its environment strongly in solution.

The high dipole moment value of the molecule $\mathbf{2}$ may make this double headed acyclo-C-nucleoside most reactive and attractive for the interaction with others systems than the molecules $\mathbf{1}$ and $\mathbf{3}$.

The spatial distributions of HOMO and LUMO are shown in Figures 6,7 and 8.

In general, HF and DFT methods give similar HOMO and LUMO orbitals.

According to DFT calculations, for the first molecule, the HOMO orbital is mainly localized on the two triazol rings (Ring A and B), while the LUMO orbital is mainly localized on triazol ring (Ring A) and around carbon chain.

For the second molecule, the HOMO orbital is mainly localized on amino-triazol ring (Ring A), while the LUMO orbital is mainly localized around carbon chain and on amino-triazol ring (Ring B).

However, for the molecule 3, the HOMO orbital is mainly localized on the oxadiazol ring (Ring A). In contrast, the LUMO orbital is mainly localized on oxadiazol ring (Ring B) in molecule 3 .

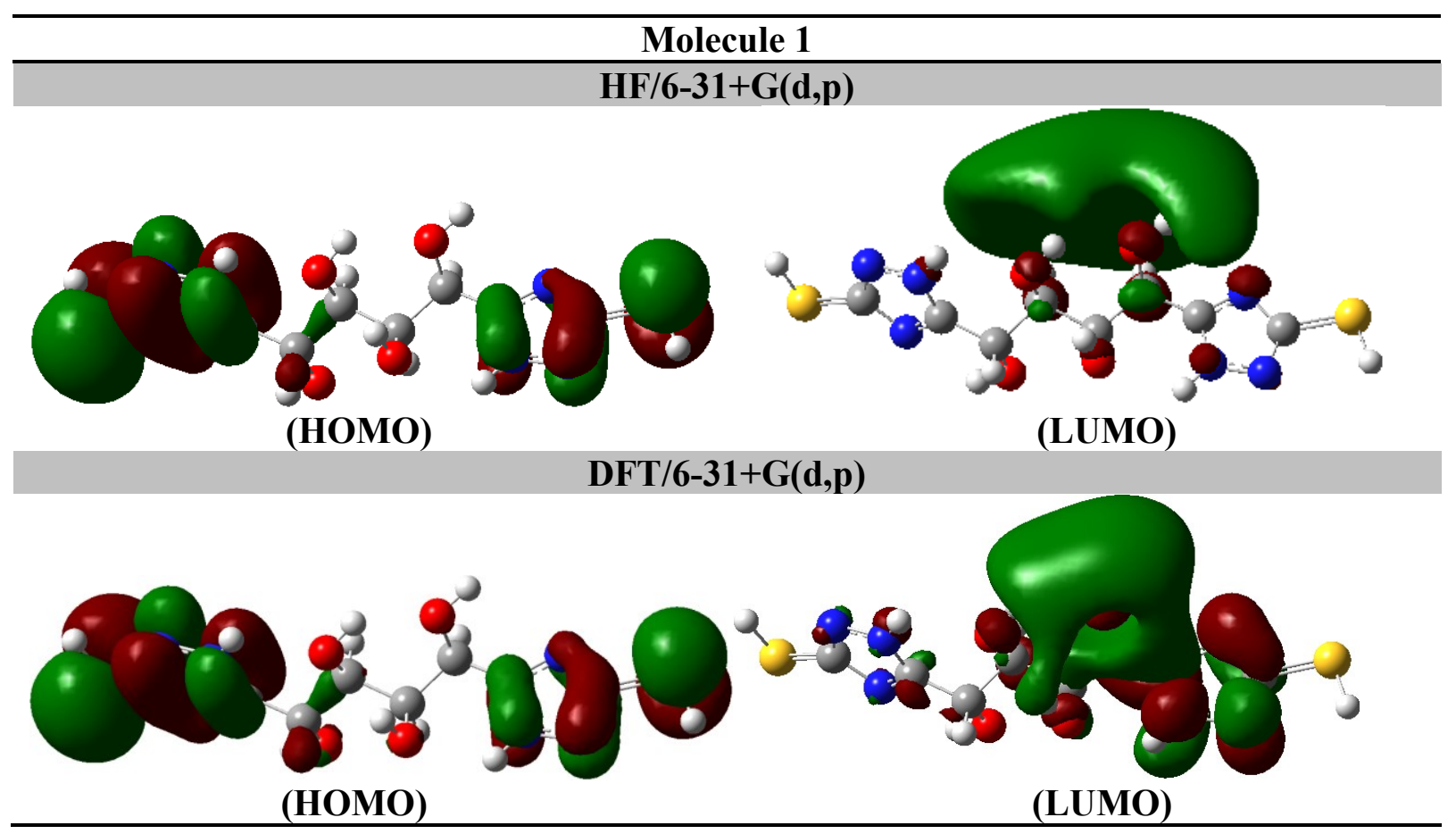

Fig. 6. 3D HOMO and LUMO plots of the molecule 1 (HF and DFT results). 


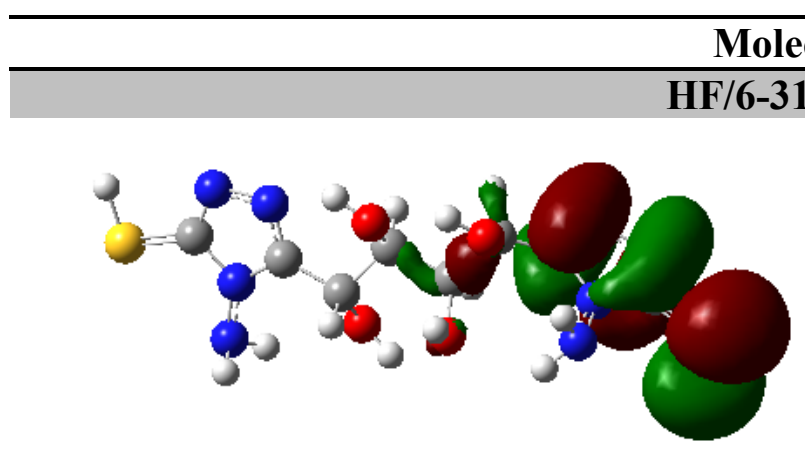

(HOMO)

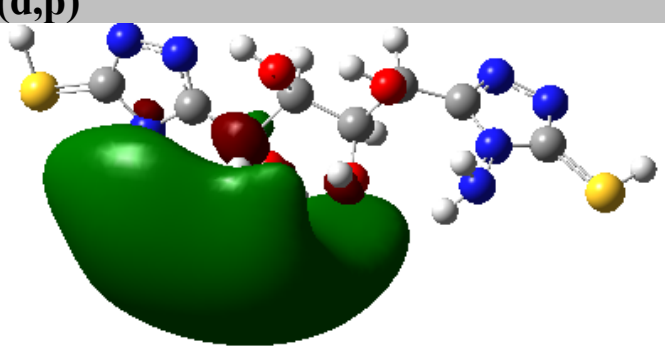

(LUMO)

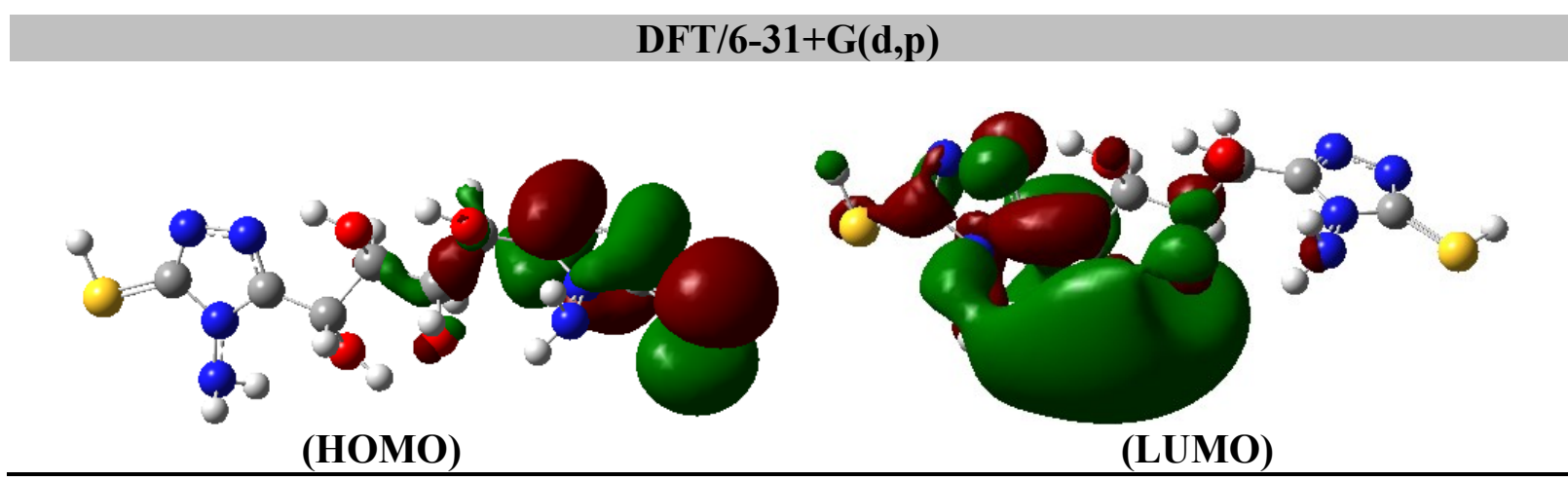

Fig. 7. 3D HOMO and LUMO plots of the molecule 2 (HF and DFT results).

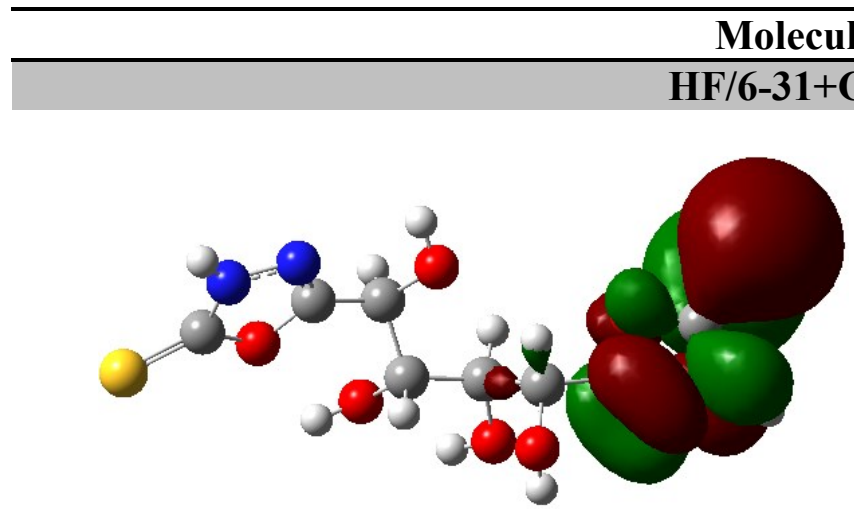

(HOMO)

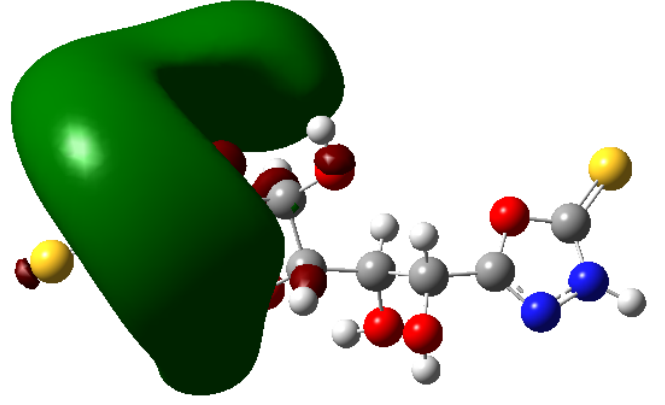

(LUMO)

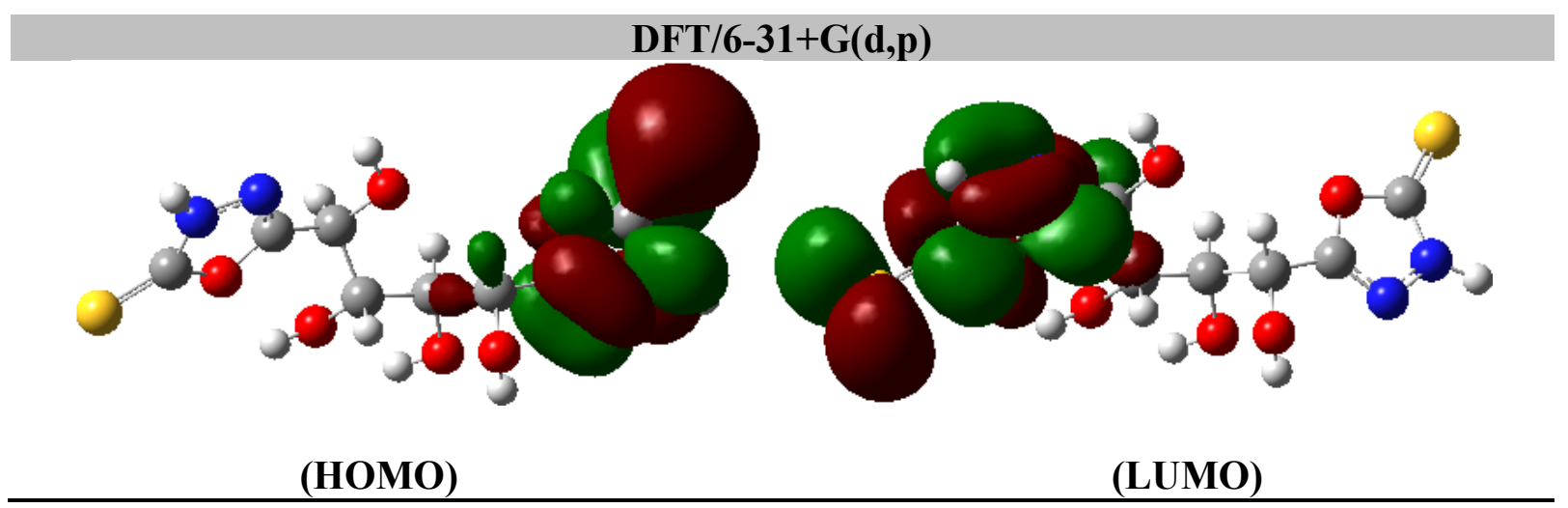

Fig. 8. 3D HOMO and LUMO plots of the molecule 3 (HF and DFT results). 
This means that these molecules don't have the same reactivity in the ground and excited states, and may be more active in the excitation state.

In order to probe the electronic differences between the molecules $\mathbf{1 , 2}$ and $\mathbf{3}$, an electrostatic surface potential (ESP) was generated. Figures 9, 10 and 11 display the ESP surface of these molecules. The gross molecular electron distribution is relatively similar with a few key differences.

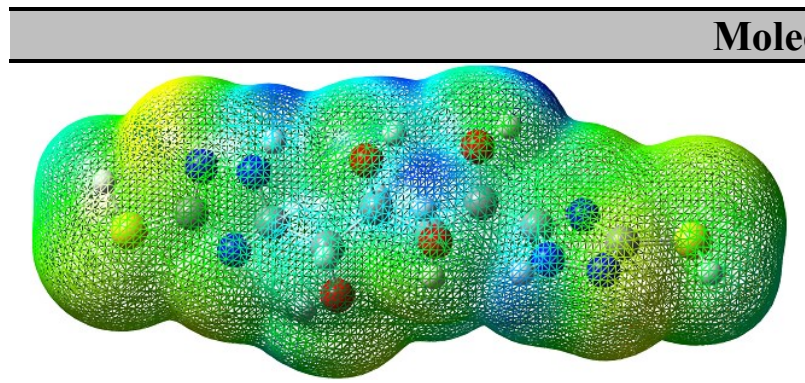

(HF)

\section{Molecule 1}

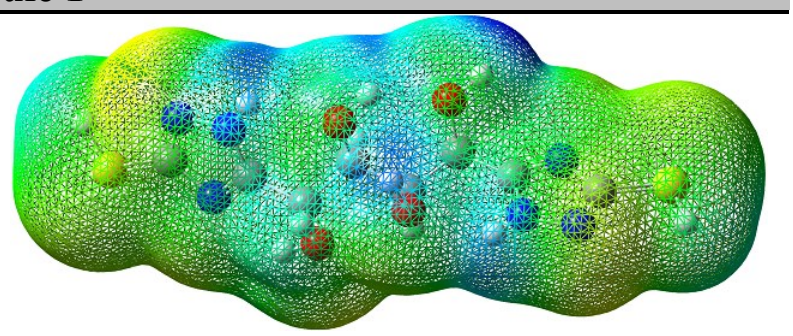

(DFT)

Fig. 9. The electrostatic potential energy surface of the molecule 1 (HF and DFT results).

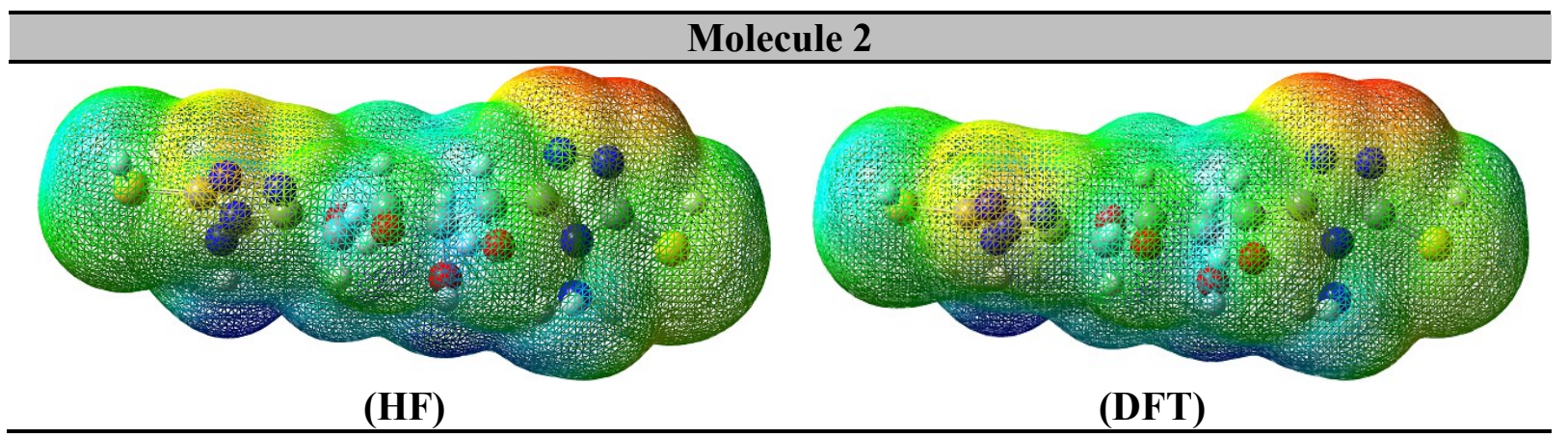

Fig. 10. The electrostatic potential energy surface of the molecule 2 (HF and DFT results).

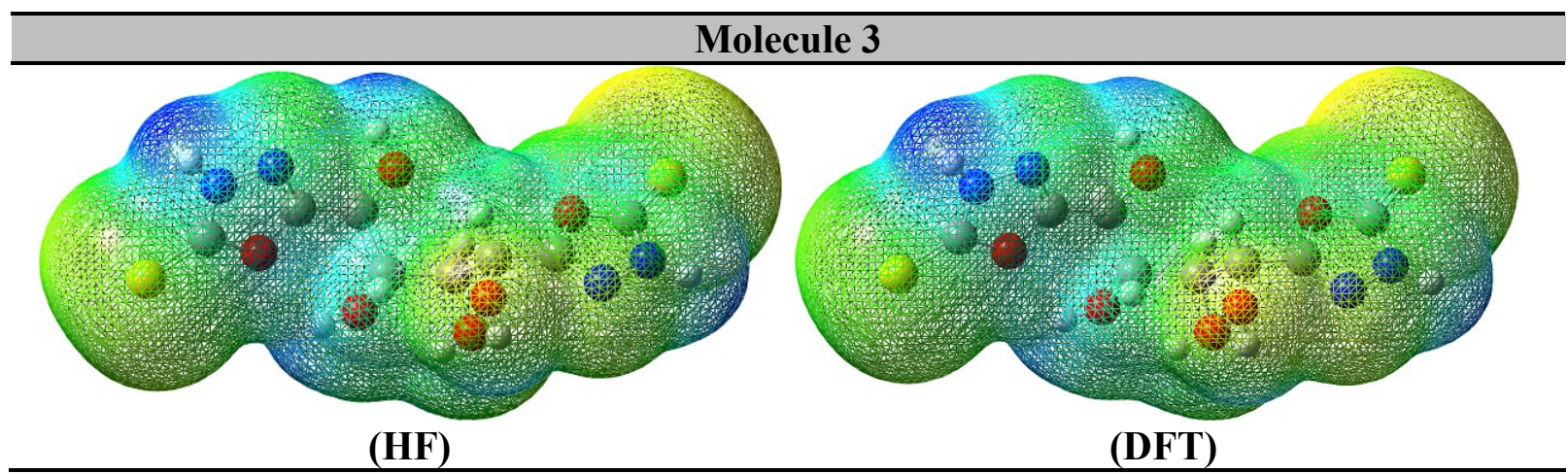

Fig. 11. The electrostatic potential energy surface of molecule 3 (HF and DFT results).

Regions colored red indicate negative ESP values and regions colored blue indicate positive values of the ESP with green being zero ESP.

1,4-bis(3-mercapto-1 $\mathrm{H}$-1,2,4-triazol-5-yl)butane-1,2,3,4-tetrol (1): The geometry optimization of AM1, HF and DFT methods yields a non-planar structure for the molecule $\mathbf{1}$.

In this molecule, some of the carbon atoms have positive excess charge, some of them have negative excess charge, the magnitude of positive charges vary from +0.046 to +0.937 (HF) and + 0.113 to +0.406 (DFT), whereas the magnitude of negative charges vary from -0.296 to -0.148 (HF) and -0.277 to -0.034 (DFT). All the oxygen atoms have negative excess charge, their 
magnitude vary from -0.706 to -0.613 (HF) and -0.632 to -0.524 (DFT). Similar to oxygen atoms, all the nitrogen atoms have negative excess charge, their magnitude vary from - 0.395 to 0.143 (HF) and -0.318 to -0.084 (DFT). The sulfur atoms have positive excess charge, their magnitude vary from +0.041 to $+0.052(\mathrm{HF})$ and +0.110 to +0.124 (DFT). Finally, all the hydrogen atoms have positive excess charge, their magnitude vary from +0.054 to +0.442 (HF) and +0.077 to +0.427 (DFT).

1,4-bis(4-amino-5-mercapto-4H-1,2,4-triazol-3-yl)butane-1,2,3,4-tetrol (2): Similar to the molecule 1, the geometry optimization of AM1, HF and DFT methods yields also a non-planar structure for the molecule 2.

For the carbon atoms, some of the carbon atoms have positive excess charge, the others have negative excess charge. According to HF calculations, the magnitude of positive charges vary from +0.035 to +0.961 , whereas the magnitude of negative charges vary from -1.109 to -0.427 . However, by DFT calculations, the magnitude of positive charges vary from +0.013 to +0.547 , whereas the magnitude of negative charges vary from -1.077 to -0.088 . All the oxygen atoms have negative excess charge, their magnitude vary from - 0.713 to -0.611 (HF) and -0.616 to -0.536 (DFT). For the nitrogen atoms, some of the nitrogen atoms have positive excess charge, the others have negative excess charge. The magnitude of positive charges vary from +0.026 to +0.247 (HF) and +0.107 to +0.381 (DFT). However, the magnitude of negative charges vary from -0.897 to 0.096 (HF) and -0.888 to -0.071 (DFT). The sulfur atoms have positive excess charge, their magnitude vary from +0.013 to $+0.082(\mathrm{HF})$ and +0.080 to +0.150 (DFT). Finally, the hydrogen atoms have positive excess charge, their magnitude vary from +0.068 to +0.451 (HF) and +0.088 to +0.429 (DFT).

5,5'-(1,2,3,4-tetrahydroxybutane-1,4-diyl)bis(1,3,4-oxadiazole-2(3H)-thione) (3): For the molecule $\mathbf{3}$, the geometry optimization of AM1, HF and DFT methods yields also a non-planar structure.

For the carbon atoms, some of the carbon atoms have positive excess charge, the others have negative excess charge. The magnitude of positive charges vary from +0.015 to +0.704 (HF) and + 0.050 to +0.255 (DFT). However, the magnitude of negative charges vary from -0.437 to -0.173 (HF) and -0.080 to -0.065 (DFT). The oxygen atoms have negative excess charge, their magnitude vary from -0.670 to -0.316 (HF) and -0.581 to -0.206 (DFT). For the nitrogen atoms, one of them has positive excess charge, the others have negative excess charge. According to HF calculations, the value of positive charge is +0.022 , the magnitude of negative charges vary from -0.523 to 0.013 . However, by DFT calculations, the value of positive charge is +0.028 , the magnitude of negative charges vary from -0.425 to -0.025 . The sulfur atoms, have negative excess charge, their magnitude vary from -0.323 to -0.280 (HF) and - 0.084 to -0.039 (DFT). Finally, the hydrogen atoms have positive excess charge, their magnitude vary from +0.130 to +0.422 (HF) and +0.145 to +0.400 (DFT).

The large charge accumulation takes place on the oxygen and nitrogen atoms. These results shown that oxygen and nitrogen atoms have more negative excess charges in compare with other atoms. This means that oxygen and nitrogen atoms undergo protonation reaction with acidic reagents.

\section{CONCLUSION}

In conclusion, the theoretical study of double headed acyclo-C-nucleosides, 1,4-bis(3-mercapto1H-1,2,4-triazol-5-yl)butane-1,2,3,4-tetrol (1), 1,4-bis(4-amino-5-mercapto-4H-1,2,4-triazol-3yl)butane-1,2,3,4-tetrol (2) and 5,5'-(1,2,3,4-tetrahydroxybutane-1,4-diyl)bis(1,3,4-oxadiazole$2(3 H)$-thione) (3), indicates that these molecules are polar and active molecules, and may interact with its environment strongly in solution. The indications reveal useful information about the 
reactivity of such molecules and about the active sites in the molecules; also, clarify the sites of molecules which undergo nucleophilic substitution or electrophilic substitution reactions.

However, further work is necessary to complete a full analysis of these double headed acyclo-Cnucleosides at a higher level of theory. The relationship between structure and biological activity of variety of double headed acyclo-C-nucleosides, appears to be one of the next logical steps.

\section{References}

[1] El Ashry ESH, El Kilany Y, Acyclonucleosides: Part 1. Seco-Nucleosides, Adv. Heterocycl. Chem. 67, 391-438, 1997.

[2] El Ashry ESH, El Kilany Y, Acyclonucle- osides: part 3. Tri-, tetra-, and pentaseconucleosides, Adv. Heterocycl. Chem. 69, 129-215, 1998.

[3] Knutsen LJS, The Chemistry of 2'-deoxyribo-C-nucleosides, Nucleosides Nucleotides, 11, 961-983, 1992.

[4] Hacksell U, Daves GD Jr, The chemistry and biochemistry of C-nucleosides and Carylglycosides, Prog. Med. Chem., 22, 1-65, 1985.

[5] Chu CK, El-Kabbani FM, Thompson BB, Determination of the anomeric configuration of Cnucleosides by 1H and 13C NMR spectroscopy, Nucleosides and Nucleotides, 3, 1-31, 1984.

[6] Buchanan JG, The C-nucleoside antibiotics, Prog. Chem. Org. Nat. Prod, 44, 243-299, 1983.

[7] Ogura H, Takahashi H, Syntheses on C-nucleosides and their Related Compounds, Journal of Synthetic Organic Chemistry, 38 (3), 756-768, 1980.

[8] Jung ME, Trifunovich ID, Efficient synthesis of 2',3'-dideoxynucleosides and 2',3'-dideoxy C-nucleosides from D-glucosamine, Tetrahedron Letters, 33(21), 2921-2924,1992.

[9] Hanessian S, Pernet AG, Synthesis of naturally occurring C-nucleosides, their analogs, and functionalized C-glycosyl precursors, Adv. Carbohydr. Chem. Biochem., 33, 111-188, 1976.

[10] Daves Jr GD, Cheng CC, The chemistry and biochemistry of C-nucleosides, Progr. Med. Chem., 13, 303-349, 1976.

[11] Watson JD, Crick FHC, The complementary structure of deoxyribonucleic acid, Proc. Roy. Soc. A, 223, 80-96, 1954.

[12] Casiraghi G, Cornia M, Rassu G, Sante CD, Spanu P, Synthesis and Transformation of Pyrrole C-Glycoconjugates, Tetrahydron, 48, 5619-5628, 1992.

[13] Kasnar B, Skaric V, Klaic B, Zinic M, A novel synthesis of double-headed nucleosides via reversed nucleosides, Tetrahedron Lett., 34 (31), 4997-5000, 1993.

[14] Jaffer M, Ebead A, Lee-Ruff E, Photochemical Synthesis of Nucleoside Analogues from Cyclobutanones: Bicyclic and Isonucleosides, Molecules, 15 (6), 3816-3828, 2010.

[15] Shuto S, Ichikawa S, Matsuda A, The first synthesis of herbicidin B, a tricyclic-sugar adenine nucleoside antibiotic, using samarium diiodide-promoted aldol-type C-glycosidation reaction as a key-step, 1999. Nucleic Acids Sympo., 42(1), 21-22.

[16] Demirbas N, Synthesis and Characterization of New Triheterocyclic Compounds Consisting of 1,2,4-Triazol-3-one, 1,3,4-Thiadiazole and 1,3,4-Oxadiazole Rings, Turk. J. Chem., 29, 125-133, 2005.

[17] Amir M, Shikha K, Synthesis and anti-inflammatory, analgesic, ulcerogenic and lipid peroxidation activities of some new 2-[(2,6-dichloroanilino) phenyl]acetic acid derivatives, Eur. J. Med.Chem., 2004. 39(6), 535-545. 
[18] El Ashry ESH, Awad LF, Winkler M, A new approach to the synthesis of nucleosides of 1,2,4-triazole, J. Chem. Soc Perkin Trans., 1(5), 829-834, 2000.

[19] Demirbas N, Karaoglu SA, Demirbas A, Sancak K, Synthesis and antimicrobial activities of some new 1-(5-phenylamino-[1,3,4]thiadiazol-2-yl)methyl-5-oxo-[1,2,4]triazole and 1-(4phenyl-5-thioxo-[1,2,4]triazol-3-yl)methyl-5-oxo- [1,2,4]triazole derivatives, Eur. J. Med. Chem., 39(9), 793-804, 2004.

[20] Kane JM, Baron BM, Dudley MW, Sorensen SM, Staeger MA, Miller FP, 2,4-Dihydro-3H1,2,4-triazol-3-ones as anticonvulsant agents, J. Med. Chem., 33(10), 2772-2777. 1990.

[21] Küçükgüzel I, Küçükgüzel SG, Rollas S, Otük-Sanış G, Ozdemir O, Bayrak I., Altuğ T, Stables JP, Synthesis of some 3-(arylalkylthio)-4-alkyl/aryl-5-(4-aminophenyl)-4H-1,2,4triazole derivatives and their anticonvulsant activity, Farmaco, 59(11), 893-901, 2004.

[22] Rollas S, Kalyoncuoglu N, Sur-Altiner D, Yegenoglu Y, 5-(4-Aminophenyl)-4-substituted2,4-dihydro-3H- 1,2,4-triazole-3-thiones: Synthesis and Antibacterial and Antifungal Activities, Pharmazie, 48(4), 308-309, 1993.

[23] Chollet JF, Bonnemain JL, Miginiac L, Rohr O, Fungicidal activity of a series of 1substituted-1-aryl-2-triazol-1-yl-ethanols, J. Pestic. Sci., 29(4), 427-435, 1990.

[24] Murabayashi A, Masuko M, Niikawa M, Shirane N, Futura T, Hayashi Y, Makisumi Y, Antifungal and plant growth inhibitory activities of stereo and optical isomers of 2triazolylcycloalkanol derivatives, J. Pestic. Sci., 16(3), 419-427, 1991.

[25] Gilbert BE, Knight V, Biochemistry and clinical applications of ribavirin, Antimicrob. Agents Chemother., 30(2), 201-205, 1986.

[26] Holla BS, Veerendra B, Shivananda MK, Poojary B, Synthesis characterization and anticancer activity studies on some Mannich bases derived from 1,2,4-triazoles, Eur. J. Med. Chem., 38, 759-767, 2003.

[27] Turan-Zitouni G, Sivaci M, Kiliç FS, Erol K, Synthesis of some triazolyl-antipyrine derivatives and investigation of analgesic activity, Eur. J. Med. Chem., 36(7), 685-689, 2001.

[28] Bekircan O, Kucuk M, Kahveci B, Kolayli S, Convenient synthesis of fused heterocyclic 1, 3, 5-triazines from some n-acyl imidates and heterocyclic amines as anticancer and antioxidant agents, Arch. Pharm., 338(8), 365-372, 2005.

[29] Wade PC, Vogt BR, Kissick TP, Simpkins LM, Palmer DM, Millonig RC, 1-Acyltriazoles as antiinflammatory agents, J. Med. Chem., 25(3), 331-333, 1982.

[30] Gruta AK, Bhargava KP, Some triazole analogs as anti-inflammatory agents, Pharmazie, 33, 430-431, 1978.

[31] Modzelewska B, Kalabun J, Synthesis and biological action of 5-oxo-1,2,4-triazine derivatives, Pharmazie, 54, 503-505, 1999.

[32] Malbec F, Milcent R, Vicart P, Bure AM, Synthesis of new derivatives of 4-amino-2,4dihydro-1,2,4-triazol-3-one as potential antibacterial agents, J. Heterocycl. Chem., 21(6), 1769-1774, 1984.

[33] Gülerman N, Rollas S, Kiraz M, Ekinci AC, Vidin A, Evaluation of antimycobacterial and anticonvulsant activities of new 1-(4-fluorobenzoyl)-4-substituted-thiosemicarbazide and 5(4-fluorophenyl)-4-substituted-2,4-dihydro-3H-1,2,4-triazole-3-thione derivatives. Farmaco, 52(11), 691-695. 1997.

[34] Ikizler AA, Johansson CB, Bekircan O, Celik C, Synthesis and antibacterial activities of some 1,2,4-triazole derivatives, Acta Polon Pharm-Drug Res., 56(4), 283-288, 1999. 
[35] Vamvakides A, Effect of some GABA, glycine, or glutamic acid derivatives on the forced swimming test in mice, Pharm. Fr., 48(3), 154-159, 1990.

[36] Hosur MC, Talawar MB, Laddi UV, Bennur RS, Bennur SC, Synthesis and antimicrobial activities of some new 1,3,4-oxadiazoles, Indian J Heterocyclic Chem., 3, 237-242, 1994.

[37] Laddi UV, Desai SR, Somannavar YS, Bennur RS, Bennur SC, Synthesis, anti inflammatory and biological activities of some new 2-mercapto-5-substituted-1,3,4-oxadiazoles, Indian Drugs, 34, 666-673, 1997.

[38] Amara S, Othman AA, A convenient new synthesis, characterization and antibacterial activity of double headed acyclo-C-nucleosides from unprotected D-glucose, Arabian Journal of Chemistry, 2012. http://dx.doi.org/10.1016/j.arabjc.2012.05.005

[39] Gaussian 09, Revision A.1, M. J. Frisch, G. W. Trucks, H. B. Schlegel, G. E. Scuseria, M. A. Robb, J. R. Cheeseman, G. Scalmani, V. Barone, B. Mennucci, G. A. Petersson, H. Nakatsuji, M. Caricato, X. Li, H. P. Hratchian, A. F. Izmaylov, J. Bloino, G. Zheng, J. L. Sonnenberg, M. Hada, M. Ehara, K. Toyota, R. Fukuda, J. Hasegawa, M. Ishida, T. Nakajima, Y. Honda, O. Kitao, H. Nakai, T. Vreven, J. A. Montgomery, Jr., J. E. Peralta, F. Ogliaro, M. Bearpark, J. J. Heyd, E. Brothers, K. N. Kudin, V. N. Staroverov, R. Kobayashi, J. Normand, K. Raghavachari, A. Rendell, J. C. Burant, S. S. Iyengar, J. Tomasi, M. Cossi, N. Rega, J. M. Millam, M. Klene, J. E. Knox, J. B. Cross, V. Bakken, C. Adamo, J. Jaramillo, R. Gomperts, R. E. Stratmann, O. Yazyev, A. J. Austin, R. Cammi, C. Pomelli, J. W. Ochterski, R. L. Martin, K. Morokuma, V. G. Zakrzewski, G. A. Voth, P. Salvador, J. J. Dannenberg, S. Dapprich, A. D. Daniels, O. Farkas, J. B. Foresman, J. V. Ortiz, J. Cioslowski, and D. J. Fox, Gaussian, Inc., Wallingford CT, 2009.

[40] Becke AD, Density-functional thermochemistry. iii. the role of exact exchange, J. Chem. Phys., 98(7), 5648-5652, 1993.

[41] Lee, C., Yang, W., Parr, R.G., Development of the Colle-Salvetti correlation-energy formula into a functional of the electron density, Phys. Rev., B 37, 785-789, 1988. 